\title{
UM POUCO DE DIGRESSÕES ACERCA DA COMPLEMENTAÇÃO VERBAL
}

\author{
José Mario Botelho (UERJ e ABRAFIL) \\ botelho_mario@hotmail.com
}

\section{Introdução}

Há muito se fala sobre a falta de eficácia da NGB (Nomenclatura Gramatical Brasileira) quanto à nomenclatura por ela sugerida aos estudiosos e interessados no assunto.

De fato, é flagrante a falta de conveniência de algumas das suas sugestões para certos fatos gramaticais, que os docentes devem adotar em suas aulas de língua portuguesa, assim como há outros que não foram prestigiados em seu texto.

Em consequência disso, muitos são os professores que criticam a NGB, uma vez que se obrigam a se limitar à adequação de suas análises àquelas normas ou a adotar uma nomenclatura própria, o que muitos têm feito para darem conta da descrição e análise de muitos fatos gramaticais. Contudo, a adoção de uma nomenclatura diferente da estabelecida pela NGB faz retornar o status quo que motivou a sua elaboração.

De certo, não se pode negar o mérito da NGB em ter posto fim ao caos que se efetivava na época, já que praticamente cada professor utilizava uma nomenclatura particular em suas aulas. No Colégio Pedro II, por exemplo, onde se concentravam diversos docentes de estimável valor e que se consideravam, cada um por si, detentores de uma nomenclatura conveniente, o problema se nos apresentava sem solução. Os discentes, vítimas de tal concorrência, tinham que assimilar uma nomenclatura a cada ano letivo, em que ocorria a mudança do docente da disciplina.

Atualmente, não vivemos tal situação, mas a ineficácia da NGB é flagrante e aponta para a necessidade de adaptações a novas nomenclaturas e adequação ou substituição de algumas que, comprovadamente, não são convenientes. 
No que se refere à complementação verbal, por exemplo, pequenas alterações se fazem necessárias.

Certos papéis temáticos dos verbos portugueses não foram prestigiados e, por isso, não receberam uma análise adequada, já que as denominações disponíveis não se enquadram convenientemente a eles.

Assim, a partir da análise desses papéis temáticos, poderemos concluir que muitas são as funções semântico-sintáticas desses elementos, o que nos faria procurar uma denominação diferente daquelas listadas pela NGB.

Considerando os estudos de Fillmore (1968), de Borba (1996) e de Cançado (2005), vamos digressionar acerca da descrição das nossas gramáticas e compêndios gramaticais, que, de certa forma, vêm seguindo as orientações da NGB.

O objetivo do presente estudo é, pois, o de apresentar subsídios para uma reflexão a respeito das denominações dadas pela tradição aos complementos e complementações dos verbos portugueses, visando a sua aplicação no ensino de análise sintática da língua portuguesa.

Logo, não pretendemos solucionar o problema de imediato, apresentando uma fórmula que dê conta de todos os casos. Pretendemos, de fato, enfatizar a necessidade de buscarmos uma forma de adequar à atual realidade a NGB, que é um instrumento necessário ao ensino de gramática da língua portuguesa.

\section{Argumentos verbais}

Entende-se por argumento verbal o elemento estrutural que lhe completa o sentido de um verbo, núcleo do predicado verbal.

Assim, o predicado verbal se define pelo número de argumentos que o seu núcleo, o verbo, exige para a expressão esteja semanticamente completa. Isto é, as expressões linguísticas constituem-se de um predicador central e seus argumentos - termos que completam o seu sentido. Na estrutura em que o predicador central é um verbo, os argumentos correspondem a um argumento de esquerda - o sujeito - 
e a um ou mais de um complemento de direita. Tanto o sujeito quantos demais argumentos são previstos pelo próprio verbo, que os subcategorizam, e podem ou não serem selecionados pelo usuário da língua, quando na elaboração de suas expressões linguísticas.

Subcategorização deve ser entendida como o fato de cada verbo selecionar a categoria gramatical de seus complementos - termos com os quais se efetiva no interior do sintagma verbal. Entendese por sintagma a unidade estrutural de sentido, que normalmente apresenta dois termos: o determinante (que pode não ser explícito) e o determinado (Ex.: "o carro"; "menina linda"; "meu irmão mais velho"; "Ele chegou.."; "Chove muito."; "Ele saiu cedo."; " mão mais velho comprou um carro novo.").

Os argumentos, que completam o sentido de um predicador, associam-se às funções sintáticas, que tradicionalmente se denomina "sujeito", "complementos direto e indireto" e determinados "adjuntos adverbiais", assim compreendido pela tradição gramatical. Podem ocorrer também numa expressão linguística estruturas que, não sendo propriamente argumentos do verbo em referência, auxiliamna, funcionando como complementação. Tais estruturas complementares, que não são exigidas pelo predicador central na formação de sentido da expressão linguística, denominam-se por adjuntos adverbiais. Tradicionalmente tais termos são considerados acessórios, já que seu uso se caracteriza como acidental, esporádico e desnecessário para a predicação do verbo, embora tenham grande importância na maioria das vezes para a expressão linguística propriamente dita.

A noção de argumentos e de adjunto é concebida por Chomsky (1986) em termos de inclusão e de continência. Para ele, um argumento é um constituinte que está incluído na projeção máxima de um núcleo com o qual se relaciona; um adjunto é um constituinte que está contido na projeção máxima de um núcleo.

Quanto ao sentido, as relações semânticas entre certo verbo e seus argumentos, que se estabelecem normalmente, constituem o que se podem chamar de papéis temáticos do verbo.

Tais papéis temáticos, que são as funções semânticas dos argumentos subcategorizados por cada predicador, compõem a competência linguística que o falante tem sobre os verbos. Essa competên- 
cia do falante lhe fornece uma lista de funções semânticas que se associam aos argumentos dos verbos. Logo, o falante faz uso desses verbos e seus argumentos de forma proficiente normalmente, mesmo que inconscientemente na maioria dos casos.

Assim, a seleção semântica constitui o que o falante sabe a respeito dos predicadores verbais de sua língua, porquanto o número de argumentos associados a uma dada função semântica dos predicadores dessa língua se define para cada usuário pelo conhecimento que detém desses predicadores e de seus argumentos, que são verdadeiras grades temáticas.

\section{Grade temática dos verbos}

Compreende-se por grade temática o conjunto de informações que um determinado item lexical de uma dada língua reúne e coloca à disposição dos usuários dessa língua para as suas eventuais expressões comunicativas.

Portanto, para cada item lexical associam-se diferentes informações semânticas, as quais podem estabelecer um ou mais de um tipo de papel temático. Ao verbo "comer", por exemplo, é-lhe associado um agente (quem come) e um paciente (o que se come), enquanto ao verbo "dormir" associa-se somente um agente (quem dorme) ou o verbo "ganhar", ao qual se associam um paciente (quem ganha), um objetivo (o que se ganha) e um agente (de quem se ganha). As expressões linguísticas poderiam ser as seguintes:

(01) O menino comeu o bolo.

(02) Meu pai dormiu.

(03) Minha mãe ganhou um presente do meu pai.

Essas informações a respeito dos papéis temáticos dos verbos encontram-se no léxico da língua em referência e fazem parte do conhecimento semântico que o usuário tem da referida língua. Normalmente, os usuários têm um conhecimento implícito do conjunto de informações da grade temática dos itens lexicais de sua língua. Conhecem a quantidade e os tipos sintáticos dos argumentos um verbo, por exemplo. Conhecem, portanto, a sua transitividade e o tipo 
de conteúdo semântico de seus complementos e podem, em consequência disso, elaborar as estruturas sintáticas nas suas práticas discursivas.

De certo, nem sempre as estruturas que completam o sentido de certos verbos obedecem a regras de regência estabelecidas pela norma padrão da língua no uso espontânea de muitos falantes. Contudo, tais regras, que são passíveis de mudanças, são assimiladas pelos usuários ao longo de sua prática discursiva, passando a fazer parte de sua competência linguística normalmente.

\section{O que são papéis temáticos?}

A noção de papéis temáticos de Gruber (1965) foi desenvolvida por Fillmore (Op. cit.), que demonstrou a sua insatisfação com as denominações tradicionais de sujeito, objeto e outros, que se mostram insuficientes para traduzir as relações semânticas dos argumentos dos verbos.

Tomemos como objeto de reflexão as seguintes estruturas sintáticas, que praticamente têm a mesma expressão:

(04) Eu abri a porta com a chave.

(04a) A porta abriu com a chave.

(04b) A chave abriu a porta.

Nas três estruturas, a função semântica do termo "a porta" é a mesma: paciente da ação de abrir. A função sintática, contudo, é diferente em cada estrutura: em (04) e em (04b), é o complemento direto ou objeto direto; e em (04a), é o sujeito. O termo "a chave" também tem a mesma função semântica nas três estruturas: instrumento da ação de abrir. Porém, em (04) e em (04a), funciona como adjunto adverbial e em (04b), como sujeito.

Percebe-se que o evento (de abrir) é o mesmo, embora as organizações das estruturas linguísticas sejam diferentes. Os participantes do evento de abrir e suas respectivas funções semânticas são os mesmos: "eu", "porta" e "chave", apesar de as funções sintáticas serem diferentes. 
As funções sintáticas e as relações estruturais entre o verbo e seus argumentos não refletem exatamente as funções e as relações semânticas que se estabelecem entre os verbos e seus argumentos. São essas relações semânticas que se denominam relações temáticas, ou papéis temáticos.

Os tipos de eventos são diversos; existem "eventos mentais" e outros que poderíamos classificar como "relacionais". Nesses eventos mentais, o ser animado pode ser um experienciador de um evento:

(05) O rapaz odeia o irmão. (experiência psicológica)

(05a) O rapaz ouvia uma bela canção. (experiência perceptiva)

(05c) O rapaz crê em Deus. (experiência cognitiva)

Embora o termo "O rapaz" seja o sujeito estrutural das três frases, não é o agente das ações expressas pelos predicadores verbais, já que não é o agente do processo em si.

A falta de relação entre o sujeito estrutural e o papel de agente, que é flagrante em (03) e nessas acima, também pode ser observado nas seguintes frases:

(05) O pneu do meu carro furou!

(06) A televisão pifou!

(07) Ela é bonita.

De fato, são muitos os papéis temáticos dos termos que compõem as grades semânticas dos diversos verbos.

\section{Papéis Temáticos, segundo Fillmore}

Eis alguns dos papéis temáticos, segundo Fillmore (Op. cit.):

a) Agente: o desencadeador de alguma ação, capaz de agir com controle.

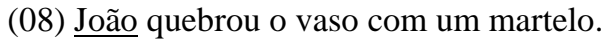

(09) Maria correu. 
b) Causa: o desencadeador de alguma ação, sem controle.

(10) As provas preocupam Maria.

(11) $O$ sol queimou a plantação.

c)instrumento: o meio pelo qual a ação é desencadeada.

(12) João colou o vaso com cola.

(13) Matei a mosca com o jornal.

d) Paciente: a entidade que sofre o efeito de alguma ação, havendo mudança de estado.

(14) $\mathrm{O}$ acidente machucou Maria.

(15) João quebrou $\underline{o \text { vaso. }}$.

e)Tema: a entidade deslocada por uma ação.

(16) João jogou a bola para Maria.

(17) $\underline{\text { A bola }}$ atingiu o alvo.

f) Experienciador: ser animado que mudou ou está em determinado estado mental, perceptual ou psicológico.

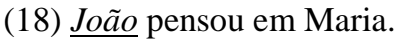

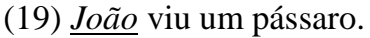

(20) João ama Maria.

g) Beneficiário: a entidade que é beneficiada pela ação verbal.

(21) João pagou Maria. 
(22) João deu um presente para Maria.

h) Objetivo (ou objetivo estativo): a entidade à qual se faz referência, sem que esta desencadeie algo ou seja afetada por algo.

(23) João leu um livro.

(24) João ama Maria.

i) Locativo: o lugar em que algo está situado ou acontece.

(25) Eu nasci em $\underline{\text { São Gonçalo. }}$

(26) O show acontece no teatro.

j) Alvo: a entidade para onde algo se move, tanto no sentido literal, como no sentido metafórico.

(27) Sara jogou a bola para o policial.

(28) João contou piadas para seus amigos.

k) Fonte: a entidade de onde algo se move, tanto no sentido literal, como no sentido metafórico.

(29) João voltou de $\underline{\text { Paris. }}$.

(30) João tirou aquela ideia do artigo do Chomsky.

\section{Complementação sob a perspectiva da NGB}

A pesquisa feita nas gramáticas e compêndios gramaticais, que seguem as orientações da NGB, revela que a complementação verbal pouco ou nada tem a ver com a noção dos papéis temáticos, estudados no item anterior.

A tradição arrola os complementos do verbo num limitado estudo sobre a transitividade dos verbos, em que se identificam apenas dois tipos de complementos: o objeto direto e o objeto indireto. Sob tal perspectiva, o sujeito, que é concebido como um termo essencial 
e não integrante do verbo, não recebe nenhuma atenção no tópico "Transitividade Verbal", que é concebida como "a potencialidade que um dado verbo tem de exigir ou não um complemento que complete o seu sentido - termos integrantes".

Assim, segundo a tradição, os verbos podem ser de um dos seguintes tipos: intransitivo, transitivo ou de ligação.

1. Verbos intransitivos - Verbos que NÃO exigem complemento; por si só têm sentido completo. Logo, quaisquer termos que se acrescentem a eles NÃO são obrigatórios, podendo, pois, ser dispensados, por serem acessórios.

(31) Os pássaros voam.

(31a) Os pássaros voam na mata.

(32) As crianças correm.

(32a) As crianças correm de um lado para o outro.

(33) O menino já foi embora.

(33a) $\mathrm{O}$ menino foi à praia ontem à tarde.

2. Verbos transitivos - Verbos que exigem um ou mais de um complemento; por si só NÃO têm sentido completo. Logo, os termos que os completam são obrigatórios e não podem ser dispensados. A eles também podem ser acrescidos termos acessórios.

a) Transitivo direto - é o verbo que exige um complemento que NÃO é iniciado por preposição necessária; isto é, o verbo se liga ao complemento diretamente, sem o auxílio de preposição.

(34) Nós fizemos os exercícios ontem à noite.

(35) Todos nós amamos (a) Deus.

Obs.: A preposição "a”, do último exemplo, foi usada para se obter ênfase, por isso pode ser dispensada, sem alteração de sentido. Neste caso, tem-se o objeto direto preposicionado. 
b) Transitivo indireto - é o verbo que exige um complemento que é iniciado por preposição necessária ("a" ou "para"); isto é, o verbo se liga ao complemento indiretamente, por meio de uma preposição necessária.

(36) A pobre mulher fala para os filhos nervosa.

(37) A notícia não agradou ao povo.

(38) Ninguém assistiu ao jogo de domingo.

c) Transitivo direto e indireto - é o verbo que exige dois complementos: um que NÃO é iniciado por preposição necessária e outro que é iniciado por preposição necessária.

(39) O aluno trouxe os cadernos para o professor.

(40) Você não mostrou as fotos aos meninos.

(41) João colocou o livro na gaveta.

3. Verbos de ligação - Verbos que ligam um predicativo ao sujeito.

(37) Paulo está muito feliz hoje.

(38) Você não anda satisfeito comigo, meu amigo!

(39) O melhor jogador do time é, sem dúvida, o Romário.

Como se pode perceber, além da omissão acerca do termo sujeito, há outras inconsistências em torno da própria identificação dos termos que acompanham os referidos verbos.

Tomemos como elemento de digressão o exemplo (32a) e (33a) do primeiro tipo de verbo, que é considerado intransitivo.

Se considerarmos válida a explicação dada para esse tipo de verbo, em que se acresce que "quaisquer termos que se acrescentem a eles NÃO são obrigatórios, podendo, pois, ser dispensados, por serem acessórios", uma contradição se apresenta de imediato. Os termos: "de um lado para o outro" e "à praia" completam o sentido dos 
verbos "correm" e "foi", respectivamente, não podendo, portanto, serem dispensados. Logo, não são acessórios.

Aliás, até mesmo os verdadeiramente acessórios (que deveriam se denominar "assessórios", já que auxiliam os verbos e seus complementos na formação de sentido da expressão linguística) não são dispensáveis à expressão linguística. São, de fato, desnecessários para a formação de uma frase oracional bimembre, que se efetiva essencialmente com sujeito e núcleo predicador (Ex.: João morreu.).

Em relação ao complemento indireto dos verbos transitivos também se pode observar uma contradição. Certamente, os termos "ao jogo de domingo" e "na gaveta", que completam o sentido dos respectivos verbos "assistiu" (exemplo (38)) e "colocou" (exemplo (41)), não são objetos indiretos, se considerarmos a acepção que a própria Tradição tem desses complementos, uma vez que observa que os complementos direto e indireto podem ser substituídos por "o" (e flexões) e "lhe" (e flexão), respectivamente (Ex.: "O aluno lhe deu o recado?", "Mostre-as para todos." e "O livro, eu já lho entreguei!").

Os termos "ao jogo de domingo" e "na gaveta" não podem ser substituídos por "lhe", mas num sintagma composto da preposição relativa ao verbo em destaque e o pronome oblíquo tônico do tipo "ele": "assistiu a ele" e "colocou nela".

Para dirimir tais inconsistências e tornar a nomenclatura atual menos contraditória, pequenas alterações poderiam ser feitas, como o fez Bechara (1999), corroborando os estudos de Rocha Lima (2005) no que se refere à transitividade verbal.

\section{Proposta de estudo sobre a transitividade verbal}

Sem a pretensão de abarcar todos os casos de complementação verbal, cuja complexidade observada no início deste estudo é flagrante, apresentamos a seguinte proposta para o estudo de transitividade verbal:

\section{Transitividade verbal}




\section{Verbos transitivos}

a) Transitivo direto - é o verbo que exige um complemento que NÃO é iniciado por preposição necessária; isto é, o verbo se liga ao complemento diretamente, sem o auxílio de preposição.

Ex.: O jardineiro regou $\underline{\text { o jardim. }}$.

Meu pai comprou um lindo carro.

b) Transitivo indireto - é o verbo que exige um complemento que é iniciado por preposição necessária ("a" ou "para"); isto é, o verbo se liga ao complemento indiretamente, por meio de uma preposição necessária.

Ex.: Maria serve de olhos para o marido cego.

A notícia não agradou ao povo.

c) Transitivo direto e indireto - é o verbo que exige dois complementos: um que NÃO é iniciado por preposição necessária e outro que é iniciado por preposição necessária.

Ex.: Você não mostrou as fotos para mim.

Entregarei o prêmio à vencedora do concurso.

d) Transitivo relativo - é o verbo que exige um complemento, a ele relacionado especificamente, que é iniciado por preposição necessária; isto é, o verbo se liga ao complemento específico indiretamente, por meio de uma preposição necessária.

Ex.: Os agricultores cuidam do campo.

Nós confiamos em suas palavras.

Ela não se refere $\underline{\underline{a} \text { você. }}$

Obs.: O complemento relativo pode ser substituído pela preposição específica, seguida de "ele" (e flexões). 
Ex.: O filme de ontem, todos assistiram a ele.

Não confie neles!

Gosto muito dela.

e) Transitivo adverbial - é o verbo que exige um complemento, iniciado por preposição necessária, que denota uma circunstância de lugar (aonde, onde ou de onde).

Ex.: Todos chegarão a casa tarde hoje.

Estava em Madureira, esperando por você.

Estamos vindo do cinema agora.

Nota: O complemento adverbial pode aparecer em forma de pronome demonstrativo (do tipo: "aqui")

2. Verbos intransitivos - Verbos que NÃO exigem complemento; por si só têm sentido completo.

Ex.: Os pássaros voam.

O menino morreu ontem.

3. Verbos de ligação - Verbos que ligam um predicativo ao sujeito.

Ex.: Paulo é realmente simpático.

Você parece um animal! 


\section{Complementos de verbos}

a) Objeto direto (OD) - é o complemento do verbo transitivo direto; isto é, é o termo que completa o sentido de um verbo, sem o auxílio de preposição necessária.

Ex.: Os meninos já prepararam o campo.

$\mathrm{O}$ carteiro entregou uma carta para mim hoje.

Ao lobo feriu o caçador.

Obs.: O complemento do terceiro exemplo é um objeto direto preposicionado.

b) Objeto indireto (OI) - é o complemento do verbo transitivo indireto; isto é, é o termo que completa o sentido de um verbo, por meio de uma preposição.

Ex.: Nós falamos para uma multidão.

O carteiro entregou uma carta para mim.

Eu sempre obedeci aos meus pais.

Nota: Os complementos podem aparecer em forma de pronome oblíquo. O pronome oblíquo "o" (os, a, as) é sempre OD; o pronome oblíquo "lhe" (lhes) é sempre OI; "me", "te", "nos" e "vos" podem ser objeto direto ou Indireto.

Ex.: Eu os vi ontem na festa. (OD)

Você já não me ama mais! (OD)

Várias pessoas disseram-lhe isto. (OI)

Meus amigos mostraram- $\underline{\underline{m e}}$ coisas lindas. (OI)

c) Complemento relativo (CR) - é o complemento de verbo transitivo relativo; isto é o termo que, relacionado especificamente a um verbo, completa o seu sentido, por meio de uma preposição necessária. 
Ex.: Você gosta de maçã?

Não creio mais em tị!

Paulo queixou-se do irmão ao pai.

d) Complemento adverbial (CAdv) - é o complemento de verbo transitivo adverbial; isto é, é o termo que, expressando uma circunstância adverbial, completa o sentido de verbo, por meio de uma preposição necessária.

Ex.: Aquele homem veio de muito longe para vê-lo.

Eu estou na sala de aula neste momento.

João, não vai para São Paulo comigo?

Fique aqui ; eu já volto!

Nota: Os pronomes demonstrativos: aqui, cá, ali, lá, acolá, algures, nenhures, podem completar o sentido de verbos transitivos adverbiais.

\section{Considerações finais}

Vimos que desde a sua implantação, a NGB tem sido criticada pela sua ineficácia quanto à padronização da nomenclatura que os docentes necessitam usar em suas aulas de língua portuguesa. De fato, é flagrante a falta de conveniência de algumas das suas sugestões para certos fatos gramaticais, assim como há outros que não foram prestigiados em seu texto. Certamente, isso obriga o professor a se limitar à adequação àquelas normas ou a adotar uma nomenclatura própria, o que retomaria o que motivou a elaboração da NGB naquela época.

Neste artigo, digressionamos acerca da transitividade verbal, demonstrando a necessidade de acréscimo de algumas poucas nomenclaturas para dar conta da análise sintática de natureza tradicional. Sob tal perspectiva, certos termos que completam o sentido dos verbos portugueses, que a NGB omitiu por razões compreensíveis, mas que devem ser repensadas inexoravelmente, foram prestigiados. 
Em seguida, consideramos outras abordagens, nas quais se valorizam os papéis temáticos dos termos, com os quais os núcleos verbais se relacionam. Logo, comprovamos que muitas são as funções semântico-sintáticas desses elementos, o que nos faz procurar denominações diferentes das que são difundidas nas nossas gramáticas e em nossos compêndios gramaticais.

Para isso, considerando os estudos de Fillmore (1968), de Borba (1996) e de Cançado (2005), comparando-os com a descrição das nossas gramáticas e compêndios gramaticais, que, de modo geral, seguem as orientações da NGB.

Esperamos que o presente estudo possa servir de subsídios para uma reflexão a respeito das denominações dadas pela tradição aos complementos e complementações dos verbos portugueses, e que possa ser utilizado no ensino de análise sintática da língua portuguesa.

\section{REFERÊNCIAS BIBLIOGRÁFICAS}

AZEREDO, José Carlos de. Fundamentos da gramática do português. 3. ed. Rio de Janeiro: Zahar, 2004. har, 2000.

. Iniciação à sintaxe do português. 8. ed. Rio de Janeiro: Za-

BECHARA, E. Lições de português pela análise sintática. 12. ed. Rio de Janeiro: Padrão, 1983.

. Moderna gramática da língua portuguesa. 37. ed. Rio de Janeiro: Lucerna, 1999.

BORBA, Francisco S., Uma gramática de valências para o português. São Paulo: Ática, 1996.

CANÇADO, Márcia. Manual de semântica: noções básicas e exercícios. Belo Horizonte: UFMG, 2005.

CARONE, Flávia de Barros. Morfossintaxe. 9. ed. São Paulo: Ática, 2001. 
CHOMSKY, Noam. Estruturas sintáticas. Trad. de Nadalena Cruz Ferreira. Lisboa: Edições 70, [1980?]. [Título original: Syntactic Structures, 1957].

. Aspectos da teoria da sintaxe. Trad. de José António Meireles e Eduardo Paiva Raposo. Coimbra: Armênio Amado Editor, 1975. [Título original: Aspects of the Teory of Syntax, 1979].

CUNHA, Celso Ferreira da; CINTRA, Luís F. Lindley. Nova gramática do português contemporâneo. 3. ed. Rio de Janeiro: Nova Fronteira, 1985.

HENRIQUES, C. C. Sintaxe portuguesa para a linguagem culta contemporânea: teoria e prática. 4. ed. Rio de Janeiro: Eduerj, 2005.

PONTES, Eunice. O tópico no português do Brasil. Campinas: Pontes, 1987.

RAPOSO, E. P. Teoria da gramática: a faculdade da linguagem. Lisboa: Caminho, 1992.

RIBEIRO, Manoel Pinto. Nova gramática aplicada da língua portuguesa. Rio de Janeiro: Metáfora, 2002.

ROCHA, A. S. da; CAMSCHO, H. Em favor do caso. Título original "The case for case. Fillmore", C. J. In: BACH, E.; HARMS, RT (Orgs.). Universals in linguistic. Nova Iorque: H. R - W, 1968, p. 188.

PERINI, Mário A. Gramática descritiva do português. São Paulo: Ática, 2000.

ROCHA LIMA, Carlos Henrique de. Gramática normativa da língua portuguesa. 45. ed. Rio de Janeiro: José Olympio, 2006.

WENCESLAU, Fábio L. Verbos beneficiários: um estudo na interface entre semântica e sintaxe. Dissertação de Mestrado, UFMG, Belo Horizonte, 2003. 